\title{
Iron deficiency aneamia is moderate public health problem among school going adolescent girls in Berahle district, Afar, northeast Ethiopia
}

\author{
Omer Seid Adem ${ }^{1,}$, , Kidane Tadsse ${ }^{1}$, Aregawi Gebremedhin ${ }^{2}$ \\ ${ }^{1}$ Department of Public Health, College of Health Science, Mekelle University, Mekelle, Ethiopia \\ ${ }^{2}$ Public Health Team Coordinator, Berahle refugee camp, Afar region, Ethiopia
}

Email address:

seoumer@yahoo.com (O. S. Adem), kiducs98@yahoo.com (K. Tadesse), yirga301@gmail.com (A. Gebremedhin)

\section{To cite this article:}

Omer Seid Adem, Kidane Tadsse, Aregawi Gebremedhin. Iron Deficiency Aneamia is Moderate Public Health Problem among School Going Adolescent Girls in Berahle District, Afar, Northeast Ethiopia. Journal of Food and Nutrition Sciences. Vol. 3, No. 1, 2015 , pp. $10-16$.

doi: $10.11648 /$ j.jfns.20150301.12

\begin{abstract}
Introduction: Anemia among reproductive age group women in Ethiopia is moderate public health problem. However, the prevalence of anemia among school going adolescent girls is not well documented yet. Objective: To determine the magnitude of anemia and associated factors among school going adolescent girls in Berahle district, Afar, northeast Ethiopia. Methodology: Institutional based cross-sectional study design was employed. Multi-stage sampling technique was used: In first stage schools were selected randomly, in the second stage in the selected schools, 338 school going adolescent girls (age 14-19 years old) were selected systematically. Structured questionnaires was used to collect Socio-demographic, socio-economic, dietary pattern and frequency of study participants. After collecting the Blood sample, Hemocue haemoglobin spectrophotometer (Hemocue HB 301 analyzer) was used to analysis hemoglobin concentration. SPSS version16.1 statistical software was used to enter and analysis the data. Bivariate and multivariate logistic regressions were used to test association among dependant and independent variables. For all statistical tests, significance level was set at p-value of 0.05 and confidence interval of $95 \%$. Result: Around one-fourth (22.8\%) of school going adolescent girls were anemic. Low Scio Economic States, AOR 2.8 (CI: 1.1, 3.7), not consuming egg AOR 2.4 (CI: 1.3, 4.3), milk consumption AOR 7.2(CI: 2.9, 17.6), not consumption of vegetables AOR 2.5 (CI: 1.3, 4.9) and meat AOR 2.4 (CI: 1.24, 4.67) were the significant causes for aneamia. Conclusion: Anemia among school going adolescent girls was moderate public health problem and Low Scioeconomic States, low consumption of egg, meat and other vegetables and high consumption of milk were the significant causes for anemia.
\end{abstract}

Keywords: School Going Adolescent Girls, Anemia, Berahile District

\section{Introduction}

Adolescence has been defined by the World Health Organization as the period of life spanning the ages between 10 to 19 years. This is the formative period of life when the maximum amount of physical, psychological, and behavioral changes take place. This is a vulnerable period in the human life cycle for the development of nutritional anemia, which has been constantly neglected by public health programs [1, 2].

Anemia is the reduction in the hemoglobin concentration of the peripheral blood below the normal range expected for age and sex of an individual. However, the determination of hemoglobin concentration should always take the state of hydration and altitude of residence of an individual into consideration [2]. The WHO defines anemia as a hemoglobin value below $13 \mathrm{~g} / \mathrm{dl}$ in men over 15 years of age, below 12 $\mathrm{g} / \mathrm{dl}$ in non-pregnant women over 15 years, and below $11 \mathrm{~g} / \mathrm{dl}$ in pregnant women [3]. It is a condition in which the number of red blood cells or their oxygen carrying capacity is insufficient to meet physiologic needs and this varies for age, sex, and altitude and pregnancy status [4].

The consequences of anemia are multiple. Iron deficiency can delay psychomotor development and cognitive performance, especially in preschool age children. Neurological manifestations may occur in children and adolescents [4]. It is a global health problem in both developing and developed countries with major consequences on human health as well as social and 
economic development [5].

Globally, $27 \%$ of adolescents in developing countries are anemic especially, in population group of school-age children and adolescent's the prevalence rate ranges from $29.2 \%$ to $79.6 \%$, [6,7]. Anemia among adolescent girls is the most prevalent nutritional problem worldwide and it is mainly caused due to iron deficiency. Its prevalence is highest among young children and women of childbearing age [8]. The prevalence of anemia is disproportionately high in the developing countries, due to poverty, inadequate diet, worm infestations, pregnancy/lactation and poor access to the health services. Adolescents are one of the major risk groups for anemia [9].

The world's adolescent population is facing a series of serious nutritional challenges which are not only affecting their growth and development but also their livelihood as adults. Yet, adolescents remain a largely neglected, difficultto- measure and hard -to- reach population, in which the needs of adolescent girls in particular, are often ignored [8]. Iron requirements peak during adolescence due to rapid growth and increase in blood volume.

The nutritional anemia in adolescent girls attributes to the high maternal mortality rate, the high incidence of low birth weight babies, high prenatal mortality and the consequent high fertility rates. This phase of life is also important due to the ever-increasing evidence that the control of anemia in pregnant women can be more easily achieved if a satisfactory iron status can be ensured during adolescence [10].

Different studies reflect inadequate nutritional iron intake generalized malnutrition or low iron bioavailability of the diet are among the causes of anemia in adolescent girls. Researches done in Africa, Asia and Latin America show that the most common risk factors associated with anemia in adolescent girls are low socioeconomic status, nonvegetarian and infection; In addition it gets precipitated by blood loss during menstruation $[7,11,12]$. However, most studies of anemia in sub-Saharan Africa have focused on children of 12 years of age with significantly fewer studies in adolescents [13].

In Ethiopia the studies conducted so far are very limited and localized, making it difficult to estimate the exact prevalence of iron deficiency anemia in the country. Some data suggest that compared to other developing countries, Ethiopia has a relatively mild prevalence of anemia. The EDHS, 2011 showed that $17 \%$ of Ethiopian women age 1549 are aneamic and it is considered to be mild. However, in some regions in the lowlands exhibited extremely high; Women in the Somali, Afar, and Dire Dawa regions have a relatively high prevalence of anaemia (44 percent, 35 percent, and 29 percent, respectively) [14]. EDHS, 2005 reported $27 \%$ of Ethiopian women are anemic [15]. These EDHS, 2011 and 2005 also reported that aneamia among 15-19 years age is $13.4 \%$ and 24.8 respectively $[14,15]$.

There has been a significant decline in the prevalence of anemia between 2005 and 2011. The efforts of the ministry of Health of Ethiopia and its stakeholders are working to tackle micronutrient deficiencies through national nutrition program to reduce the prevalence of anemia among adolescent girls to $13 \%$ up to the end of $2015[16,17]$. But the recent demographic health survey EDHS, 2011 report the prevalence of anemia in women reproductive age group in Afar remains unacceptably high (34.8\%) which is one of the highest in Ethiopia.

Even though different studies have been conducted about the magnitude of anemia in reproductive age group from1549 years which largely varies from region (highest in Afar 79.4\% and lowest in Addis Ababa 7.5\% ) [18] to region and study done on prevalence of anemia among Ethiopian Women found $30.4 \%$ of them were anemic[20].

In general carefully reviewed literatures showed that nutritional anemia is a public health problem of nutritional importance among Ethiopia women. Surprisingly there is a limited study (literary no study) about the magnitude of anemia among adolescent girls Ethiopia and in the study district. Low Landers are extremely affected than high Landers. Afar region and Berahle found in the region is one of the lowest altitude areas in Ethiopia even in the world. Therefore, the current study is conducted on adolescents found in the low land part of Ethiopia in particularly Afar region, Berahle district; to assess the magnitude and associated factors of anemia among school going adolescent girls.

\section{Method and Materials}

Study area and period: Afar regional state is one of the nine regions of Federal Democratic Republic of Ethiopia. Berahle one of the districts found in Afar region, which is located $903 \mathrm{~km}$ north east of the capital of Ethiopia Addis Ababa and $620 \mathrm{~km}$ from Semera (the regional town of Afar region). It is bounded northeast with Eritrea, western with Tigray regional state, in south with Abaala district, North West Dallol district and with Afdera district in Eastern part. Average altitude of the district is $905 \mathrm{~m}$ above sea level. The total population of the District is 93,728 [21]. The study was conducted in August, $/ 2014$.

Study Design: School based cross-sectional study design was employed.

Populations: All adolescent girls of governmental schools of Barahle district age 14- 19 years were the source populations. All adolescent girls found in the randomly selected schools were the study populations then the study unites were systematically selected in this schools.

Sample size Determination: The sample size was calculated using Epi open software. The total sample size was 338 at $95 \%$ confidence interval, margin of error $5 \%$ and $\mathrm{p}=34.8 \%$ (the proportion of anemia among reproductive age group in Afar region is 34.8\%) [14].

Sampling Procedure: Multi stage sampling technique was used. The $1^{\text {st }}$ stage; six schools were selected randomly out of eight schools found in the District. The $2^{\text {nd }}$ stage study subjects were selected using systematic random sampling technique. Sampling frame of the students who were in the age range of 14-19 years old from roster was made among 
the listed students.

Data collection procedure: Female data collectors were used for confidentiality reason. The educational level of the parents was classified as low (illiterate or less than secondary school education), medium (secondary school education), or high (college or university education). A household standard of living index was devised based on household possessions. A score of 1 was given to ownership of each of the following items: family mobile phone, toilet (any type), Radio, Fan(air conditioner), water pipes, refrigerator, bed ,own farm land, cattle, camel, goat, sheep, hen, television, electric and own house. The scores were summed to give a standard of living score range of $0-16$. Three categories were constructed: "low", $\leq$; "medium", 7-10 and "high", 11-16 [32].

Hemoglobin: Capillary blood sample was taken by pricking from the tip of finger in aseptic way to determine hemoglobin level. Hemoglobin analysis was carried out using Hemocue haemoglobin spectrophotometer (Hemocue HB 301 analyzer). The 10 micro liter blood sample was collected by finger pricking after rubbing the finger tip with sterile cotton (immersed in alcohol), and pricking it with a sterile disposable lancet. Blood sample collection and hemoglobin concentration analysis was done immediately after interviewing the subjects by data collectors at their respective schools. A drop of blood was allowed to enter the optical window of the microcuvette through capillary action. The microcuvette was placed into the cuvette holder for photometric determination of hemoglobin level. Then, the concentration of hemoglobin level was quantitatively determined with in fifteen seconds read in $\mathrm{g} / \mathrm{dl}$ and recorded. The sample blood would never be used for further investigation other than hemoglobin analysis and subject were informed accordingly.

Data Quality: Pretested and local language translated questionnaire was used for data collection. Training was given for data collectors and supervisors. Correction was made for incomplete questioners during data collection. The criteria of anemia were accepted after adjusted hemoglobin value for Altitude and temperature.

Data analysis: The data was coded, entered and cleaned then analyzed using SPSS software version 16.1. Frequencies, percentage, mean and standard deviation were used for the descriptive analysis. Bivariate logistic regression model was used to the test association among dependant and independent variables one by one then variables that were significant in bivariate also checked in multivariate logistic regression. For all statistical tests, significance level was set at p-value of 0.05 . Results are presented using OR and 95\% CI.

Ethical considerations: The study protocol was reviewed and approved by the Institutional Ethical Review Board College of Health Sciences of Mekelle University. Permission to undertake the study was obtained from every relevant authority in the Woreda (District) Educational Authorities and School Principals. The nature of the study was also fully explained to the school directors and teachers. To obtain written consent study participants and their parents were informed prior to participation in the study. Both the students and their parents were aware about the study doesn't affect their health, they are selected randomly, they don't have direct benefit, they have the right not participated and data were kept confidential. The participated students have the right to know their anemia states and for these who were anemic linking to the nearest health facility was made.

\section{Result}

Scio-demographic and economic characteristics: The mean $\pm \mathrm{SD}$ age in year of the study participants was $16 \pm 1.7$. Majority of the participants came from 5-6 member families (47.3\%) 160 and $>7$ members' families (37.6\%) 127. Two every three $(66.3 \%) 224$ were from extended families. Most of the students (77.5\%) 262 were single and the rest were married. More than half $(61.2 \%)$ of the participants were rural resident and Islam is the predominant religion (95\%) 321. More than half (52.1\%) 176 of the adolescent girls came from family with low socioeconomic status (LSES). Above half (57.4\%) 194 respond that the primary sources of food for their families were purchased (Table -1).

Table 1. Secio-demographic and economic characteristics of school going adolescent girls in Berahle, Afar, Northeast Ethiopia, August 2014 (N=338).

\begin{tabular}{|c|c|c|c|}
\hline Characteristics & & Frequency & Percentage \\
\hline \multirow{3}{*}{ Age in year } & $14-15$ & 117 & 34.6 \\
\hline & $16-17$ & 124 & 36.7 \\
\hline & $18-19$ & 97 & 28.7 \\
\hline \multirow{3}{*}{ Ethnicity } & Afar & 317 & 93.8 \\
\hline & Tigray & 16 & 4.7 \\
\hline & Amhara & 5 & 1.5 \\
\hline \multirow{2}{*}{ Religion } & Muslim & 322 & 95.3 \\
\hline & Orthodox & 16 & 4.7 \\
\hline \multirow{2}{*}{ Residence } & Urban & 131 & 38.8 \\
\hline & Rural & 207 & 61.2 \\
\hline \multirow{2}{*}{ Family type } & Nuclear & 114 & 33.7 \\
\hline & Extended & 224 & 66.3 \\
\hline \multirow{3}{*}{ Family size } & $\operatorname{Low}(<4)$ & 51 & 15.1 \\
\hline & Medium(5-6) & 160 & 47.3 \\
\hline & $\operatorname{High}(>7)$ & 127 & 37.6 \\
\hline \multirow{3}{*}{$\begin{array}{l}\text { Mothers' } \\
\text { educational } \\
\text { status }\end{array}$} & Low & 319 & 94.4 \\
\hline & Medium & 13 & 3.8 \\
\hline & High & 6 & 1.8 \\
\hline \multirow{3}{*}{$\begin{array}{l}\text { Fathers' } \\
\text { educational } \\
\text { status }\end{array}$} & Low & 280 & 82.8 \\
\hline & Medium & 29 & 8.6 \\
\hline & High & 29 & 8.6 \\
\hline \multirow{6}{*}{$\begin{array}{l}\text { Fathers' } \\
\text { occupation }\end{array}$} & Employee & 47 & 13.9 \\
\hline & Farmer & 57 & 16.9 \\
\hline & Merchant & 47 & 13.9 \\
\hline & daily laborer & 27 & 8.0 \\
\hline & Pastoralist & 156 & 46.2 \\
\hline & Others & 4 & 1.2 \\
\hline \multirow{5}{*}{$\begin{array}{l}\text { Mothers } \\
\text { occupation }\end{array}$} & Employee & 36 & 10.7 \\
\hline & Pastoralist & 60 & 17.8 \\
\hline & Housewife & 208 & 61.5 \\
\hline & Merchant & 25 & 7.4 \\
\hline & Others & 9 & 2.7 \\
\hline \multirow{2}{*}{ SES } & Low SES & 176 & 52.1 \\
\hline & Medium & 162 & 47.9 \\
\hline \multirow{4}{*}{$\begin{array}{l}\text { Primary source } \\
\text { food for the } \\
\text { family }\end{array}$} & own product & 47 & 13.9 \\
\hline & Purchased & 194 & 57.4 \\
\hline & Borrowed & 24 & 7.1 \\
\hline & food aid & 73 & 21.6 \\
\hline
\end{tabular}


Dietary Pattern: Meal frequency, (69.5\%) 235 had three meals/ day whereas $(30.5 \%) 103$ of them had two times/ day. Sixty one percent (206) of the participants had regular meal time and the rest (39\%) 132 had irregular meal time. Among who had irregular meal time (75\%) 99 of the skip breakfast, (17.6\%) 23 skip lunch and (7.6\%) 10 were skip dinner. More than half $(53.6 \%) 181$ of the participants took tea/and coffee immediately (Before $30 \mathrm{~min}$ ) after meal.

Dietary frequency: A large proportion of the participants consumed meat (65.5\%) 221, fish (98.42\%) 333 and eggs $(51.4 \%) 174$ three times less in the week preceding the interview. A substantial proportion of the girls did not take other vegetables (51.8\%) 175 and liver (87.9\%) 297 at all in the week. More than one-third (38.2\%) 129 did not take leafy vegetables; while substantial proportions of the participants had milk (45.6\%) 154 three times and above in the week (Table-2).

Table 2. Frequency intake of selected food items by adolescent school girls in Berahle, Afar, Northeast Ethiopia, August 2014 (N=338).

\begin{tabular}{|c|c|c|c|}
\hline \multirow{2}{*}{ Food item } & \multicolumn{3}{|c|}{ Frequency food item/week } \\
\hline & None (0 \%) & $1-2$ timer in \% & $\geq 3$ times in $\%$ \\
\hline Meat & 54.1 & 10.4 & 35.5 \\
\hline Fish & 87.6 & 8.6 & 3.8 \\
\hline Egg & 32.5 & 18.9 & 48.5 \\
\hline Liver & 87.9 & 8.3 & 3.8 \\
\hline Milk & 26.3 & 28.1 & 45.6 \\
\hline Leafy vegetables & 38.2 & 13.6 & 48.2 \\
\hline Other vegetables & 51.8 & 15.1 & 33.1 \\
\hline Fruits & 4.7 & 23.1 & 72.2 \\
\hline
\end{tabular}

Menarche: The mean age at menarche was $13.41 \pm 1.18$ years. Only $25(7.4 \%)$ of the girls had their menarche before the age of 12 years (Table-3).

Table 3. Frequency of age at menarche of school adolescent girls in Berahle district, North-east, Ethiopia, August 2014 (N=335).

\begin{tabular}{lll}
\hline Age in years & Frequency & Percentage \\
\hline 11 & 25 & 7.4 \\
12 & 46 & 13.6 \\
13 & 94 & 27.8 \\
14 & 120 & 35.5 \\
15 & 38 & 11.2 \\
16 & 12 & 3.6 \\
Total & 335 & 99.1 \\
\hline
\end{tabular}

Three girls had not yet attained their menarche
Magnitude and severity of aneamia: The overall prevalence of aneamia was found $(22.8 \%) 77$. The overall mean of hemoglobin was $12.7 \mathrm{mg} / \mathrm{dl}(\mathrm{SD} \pm 1.6)$ (Figure-1).

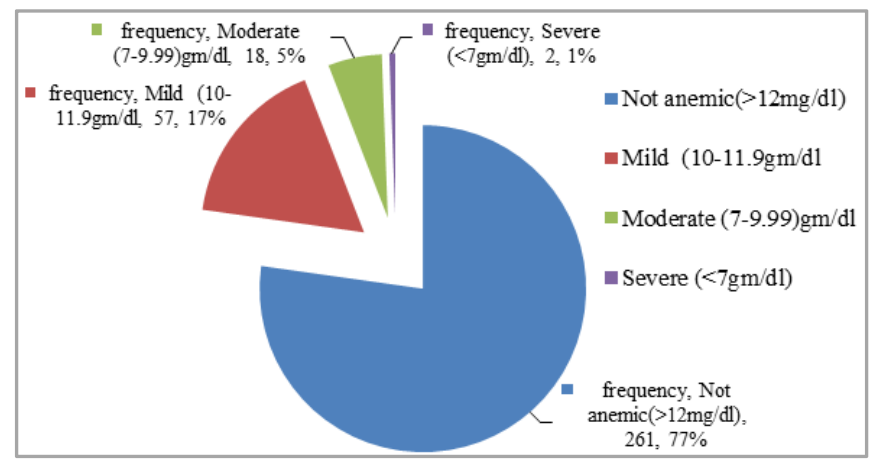

Figure 1. Magnitude of anemia among school going adolescent girls in Berahle, Northeast Ethiopia, August 2014 (N=338).

Associated Factors: Bivariate analysis showed that rural residents were 2.1 times (COR 2.1, CI: 1.18-3.7) more likely anemic than urban. Having large family size (having $>7$ members) were 3.23 times (COR 3.23, CI: 1.18-8.8) more likely anemic than low family size. Adolescents from LSES family were 2.9 times (COR 2.9 (CI: 1.3-4.3) more likely anemic than medium SES. Adolescents not consuming/ week of meat, egg, vegetable and fruits were 2.5 times (COR 2.5, CI: 1.24-4.07), 2.4 times (COR 2.4, CI: 1.3-4.3), 2.4 times (COR 2.4, CI: 1.3-4.3) and 4.9 times (2.4, CI: 1.75-13.9) more likely aneamic than consuming greater/equals three times /week respectively. However, those greater/equals three times/week milk consumers were 5.9 times aneamic compare with none consumers (COR 5.9, CI: 2.57-13.84). In multivariate analysis, the major determinants identified for anemia in the current study were only SES, low frequency of meat, vegetables, egg, fruits and highly frequent consumption of milk to anemia. After controlling all other factors the risk of being anemic was 2.1 (CI: 1.2-3.7) times higher among students came from low SES as compared to medium SES. Participants who consumed milk three times and above were 6.9 (CI: 2.8-17) times more likely to be anemic as compared with those who did not consumed even once per week. The risk of be anemic of those who consume milk 1-2 times per week was 3.3 times higher than that of who had never consumed at all per week(Table-4).

Table 4. Logistic predictors of anemia among adolescent girls in Berahle, Northeast Ethiopia, August 2014 (N=338)

\begin{tabular}{|c|c|c|c|c|c|}
\hline \multirow{2}{*}{ Predictors } & \multirow{2}{*}{ Category } & \multicolumn{2}{|c|}{ Hemoglobin status } & \multicolumn{2}{|c|}{ Odd ratio (95\% CI) } \\
\hline & & Aneamic & Not anemic & COR & AOR \\
\hline \multirow{2}{*}{ Residence } & Rural & 75 & 150 & $2.1(1.18,3.7$ & $1.8(0.98,3.64)$ \\
\hline & urban & 20 & 111 & 1 & 1 \\
\hline \multirow{3}{*}{ Family size } & $\operatorname{Low}(<4)$ & 5 & 46 & 1 & 1 \\
\hline & Medium(5-6) & 39 & 121 & $2.96(1.1,7.9)$ & $2.48(0.85,7.2)$ \\
\hline & $\operatorname{Large}(>7)$ & 33 & 94 & $3.23(1.18,8.82)$ & $2.49(0.84,7.4)$ \\
\hline \multirow{2}{*}{ SES } & Low & 25 & 137 & $2.3(1.35,2.9)$ & $2.1(1 \cdot 2,4 \cdot 3)^{*}$ \\
\hline & Medium & 52 & 124 & 1 & 1 \\
\hline \multirow{3}{*}{ Egg } & Zero & 25 & 139 & $2.4(1.3,4.3)$ & $2.02(1.02,3.9)^{*}$ \\
\hline & 1-2 times/ week & 19 & 45 & $2.1(1.2,4.6)$ & $2.1(0.98,4.6)$ \\
\hline & $\geq 3$ times/week & 33 & 77 & 1 & 1 \\
\hline
\end{tabular}




\begin{tabular}{|c|c|c|c|c|c|}
\hline \multirow{2}{*}{ Predictors } & \multirow{2}{*}{ Category } & \multicolumn{2}{|c|}{ Hemoglobin status } & \multicolumn{2}{|c|}{ Odd ratio $(95 \% \mathrm{CI})$} \\
\hline & & Aneamic & Not anemic & COR & AOR \\
\hline \multirow{4}{*}{ Milk } & Zero & 7 & 82 & 1 & 1 \\
\hline & 1-2 times/week & 18 & 77 & $2.73(1.08,6.9)$ & $3.3(1.2,9)$ \\
\hline & $\geq 3$ times/week & 52 & 102 & $5.9(2.57,13.84)$ & $6.9(2.8,17.0)^{*}$ \\
\hline & Zero & 7 & 39 & $2.4(1.3,4.3)$ & $2.2(1.2,4.3)^{*}$ \\
\hline \multirow{3}{*}{ vegetables } & 1-2 times / week & 26 & 137 & $0 .(0.34,2.3$ & $1.1(0.4,3.1)$ \\
\hline & $\geq 3$ times/week & 27 & 83 & 1 & 1 \\
\hline & Zero & 18 & 102 & $2.5(1.24,4.07)$ & $2.4(1.24,4.67)^{*}$ \\
\hline \multirow[t]{3}{*}{ meat } & 1-2 times/week & 7 & 20 & $1.4(0.54,3.7)$ & $1.7(0.61,5.1)$ \\
\hline & $\geq 3$ times/week & 52 & 131 & 1 & 1 \\
\hline & Zero & 8 & 8 & $4.9(1.75,13.9)$ & $5.1(1.5,18)$ \\
\hline \multirow[t]{2}{*}{ fruits } & 1-2 times/week & 28 & 50 & $2.7(1.5,4.9)$ & $1.75(0.9,3.4$ \\
\hline & $\geq 3$ times/week & 4 & 203 & 1 & 1 \\
\hline
\end{tabular}

* Stands for Variables that are significant in multivariate analysis.

\section{Discussion}

Anemia among adolescent girls is the most prevalent nutritional problem worldwide and it is mainly caused due to iron deficiency. Adolescents are one of the major risk groups for iron anemia [9]. Globally, 27\% of adolescents in developing countries are anemic especially, in population group of school-age children and adolescent's the prevalence rate ranges from $29.2 \%$ to $79.6 \%,[6,7]$. The current study showed that, $22.8 \%$ of school going adolescent girls were anemic which was a moderate public health significance based on the WHO (15-35\%) standards [21]. The present study showed that remarkable reduction as compared with the prevalence of anemia of Afar region among reproductive age group 34.8\% (from EDHS, 2011) and the national prevalence of 15-19 years age adolescents (24.8\%) (from EDHS, 2005).

Another study conducted nine regions of Ethiopia showed that, $79.4 \%$ of Afar region, $44 \%$ of Somali region and $28.7 \%$ of Dire dawa town administration reproductive age group women were anemic $[18,19]$. The Somalia region and Dire dawa town administration are the neighbor of the study region with similar food habits and geographical altitude. In this case the variation might be due to age difference and parity of study participants. Or, could be due to the effort of the government of Ethiopian Ministry of Health by implementation of many related programs including the Essential Nutrition Action, National nutrition program and community based nutrition intervention. Or other probable causes of this low prevalence may be; One: Even though, the current study was conducted in schools both rural and urban areas but considerable number of students came from urban population in Berahle town with a better health condition in comparison to rural population. Second: the study was limited to the adolescent girls in schools, which relatively they have higher socioeconomic status and knowledge than those who are not attending the schools.

However the current study result is higher than report from the recent EDHS, 2011the national average prevalence of anemia among girls whose age 15-19 years was $13.4 \%$, which was by far low from the current magnitude of anemia. This big variation could be due to, milk based staple food habit (Milk inhabits the bioavailability of iron) and geographically low altitude (where hemoglobin concentration is low) of the study area which, is unlike cereal and legume based staple food of highlanders of majority part of Ethiopia. Means the magnitude of anemia is remarkably reducing because of the above motioned reasons and other in Ethiopia. But, the redaction is more sluggish in Lowlands than in highlanders because of the food habit and altitude.

Aneamia among adolescent girls are multi-factorial. Like socio-economic status, dietary behavior/pattern (intake of iron reach foods, Iron absorption and bioavailability enhancers and inhibitors), socio-demographic factors, infection/infestation and menarche status. Researches done in Africa, Asia and Latin America show that the most common risk factors associated with anemia in adolescent girls are low socioeconomic status, non-vegetarian and infection; In addition it gets precipitated by blood loss during menstruation $[7,11,12]$. In the current study, adolescent girls from LSES families were 2.1 times anemic than from medium SES families. Which is a consistent study done in Turkey and Palestine Meerut [22, 23]. In this case, it is not imposable to say poverty is one cause for iron deficiency aneamia.

Family size was found as determinant factor for high prevalence of anemia among adolescent girls in different studies $[23,24]$. Even though, majority of the participants in this study were from medium and large family (Table-1), it was not significantly associated with aneamia. Unlike this similar study from Bangladesh showed adolescents from medium- (5-6 members) and large ( $>7$ members) sized families were positively association with anemia. The variation might be due to most participants were come considerable similar family size and their maternal and paternal educational level was similar.

Consumption of tea and coffee after taking meal is the well known anti-nutritional factors that inhabit the bioavailability of iron. However, in the current study no association between taking coffee/and tea and anemia, unlike Meerut showed association [22]. The current study found that participants who consumed milk three times and above per week were 6.9 times more likely to be anemic than who had never consumed even once per week. And participants who had 
even 1-2 times per day were 3.3 more likely to be anemic than those who had never consumed per week. In line with this study, in Nigeria there was high prevalence of anemia among those who had frequent dairy diet [25]. Which is because of the reason milk has high concentration of calcium and casein which are potent inhibitors of non-heme iron in diet unlike heme iron and a competitive absorption inhabitation of calcium with iron in the intestine study conducted in Bangladesh showed this this[26].

Among the foods that were positively associated with anemia in the current study were low consumption of meat, fruits and egg (Table-4). Animal products have several micronutrients that prevent anemia. It is reported that vitamin B12 deficiency may be quite common in developing countries where intake of animal products is low. It is necessary for the synthesis of red blood cells and its deficiencies have been associated with anemia [27]. HemeIron is abundant in animal products and has high affinity to bind with hemoglobin. Therefore, diets with little or no animal protein, as it is often the case in the developing world, coupled with mala-absorption. Folic acid is also essential for the formation and maturation of red blood cells and necessary for cell growth and repair. Deficiency of folate reduces the rate of DNA synthesis with consequent impaired cell proliferation and intramedullary death of resulting abnormal cells. This shortens the lifespan of circulating red blood cells and results in anemia [28]. Inadequate intake of Fruits and other vegetables were also associated with anemia in this study. Since fruits and other vegetable are good, source of Vit-A, and Vit-C and those are also the good Iron absorption enhancers [28,29,30].

\section{Conclusion}

Aneamia among school going adolescent girls is moderate public health problem in Berahle district. Being from low socioeconomic states family, high frequency consumption of milk and low frequency consumption of meat, egg fruits and other vegetables were significant association factor for aneamia.

\section{References}

[1] Chaudhary SM, Dhage VR. A study of anemia among adolescent females in the urban area of Nagpur. Indian J. Community Med 2008; 33:243-5.

[2] Iron deficiency anaemia: assessment, prevention, and control. A guide A guide for programme managers. Geneva, World Health Organization, 2001 (WHO/NHD/01.3).

[3] World Health Organization. Nutritional anemia: report of a WHO Scientific Group. Geneva, Switzerland, 2002.

[4] World Health Organization. WHO Vitamin and Mineral Nutrition/ Anemia 2011

[5] World Health Organisation. Worldwide prevalence of anaemia 1993-2005: WHO global database on anaemia 2005.
[6] Abidoye RO, PA Akande. Nutritional status of public primary school children: a comparison between an upland and riverine area of Ojo Local Government Area, Lagos State Nigeria. Nutrition Health. 2000; 14: 225-240.

[7] Tatala SR, Kihamia CM, Kyungu LH, Svanberg U. Risk factors for anemia in schoolchildren in Tanga Region, Tanzania. Tanzan Journal of Health Research 2008; 10(4):189-202.

[8] World Health Organization. National Strategies for Overcoming Micronutrient Malnutrition. Geneva, WHO, 1991.

[9] Premalatha T, Valarmathi S, Srijayanth P, Sundar JS, Kalpana S. Prevalence of anemia and its Associated Factors among Adolescent School Girls in Chennai, Tamil Nadu, INDIA. Epidemiology201 2; 118:10.4172.

[10] Kaur S, Deshmukh PR, BS Garg. Epidemiological correlates of nutritional anaemia in adolescent girls of rural Wardha. Indian J Community Med 2006; 31:255-58.

[11] World Health Organization. World Health Statistics 2005. Geneva, World Health Organization 2005.

[12] Meenal Vinay Kulkarni, P M Durge, N B Kasturwar; prevalence of anemia among adolescent girls in an Urban Slum. National Journal of Community Medicine2012; 3 (1) 1177.

[13] Leenstra T, Kariuki SK, Kurtis JD, Oloo AJ, Kager PA and FO ter Kuile. Prevalence and severity of anemia and iron deficiency in adolescent schoolgirls in western Kenya. European Journal of Clinical Nutrition2004; 58, 681-691.

[14] Central Statistical Agency (Ethiopia) and ORC Macro. 2010. Ethiopia Demographic and Health Survey 2011.

[15] Central Statistical Agency (Ethiopia) and ORC Macro. 2006. Ethiopia Demographic and Health Survey 2005. Addis Ababa, Ethiopia.

[16] Mhairi A Gibson,An. An Energy-Saving Development Initiative Increases Birth Rate and Childhood Malnutrition in Rural Ethiopia. PLoS Med20063 (4): e87.doi:10.1371/journal. pmed.0030087.

[17] Gies S, Brabin BJ, Yassin MA and LE Cuevas. Comparison of screening methods for anemia in pregnant women in Awassa, Ethiopia. Trop Med Int Health 2003; 8:301-9.

[18] Haidar J, Melaku U, Pobocik RS. Iron and Folate deficiency in women of reproductive age in nine administrative regions of Ethiopia: an emerging public health problem. S Afr J Clin Nutr 2010; 23(3):132-137.

[19] Jemal Haidar. Prevalence of Anaemia, Deficiencies of Iron and Folic Acid and Their Determinants in Ethiopian Women. J Health Popul Nutr. Aug 2010; 28(4): 359-368.

[20] Ramzi M, Haghpanah S, Malekmakan L, Cohan N, Baseri A, Alamdari A, and N Zare. Anemia and Iron Deficiency in Adolescent School Girls in Kavar Urban Area, Southern Iran. Iran Red Crescent Med J 2011; 13(2):128-133.

[21] Kurz KM. Adolescent nutritional status in developing countries. Proc Nutr Soc 1996; 55:321-331.

[22] Rita singh. Socio-demographic factors causing anaemia in adolescent girls in meerut; Health and Population Perspectives and Issues 2008Vol. 31 (3), 198-203. 
[23] Yasemin Ișik Balc, Aysun Karabulut, Dolunay Gürses, İbrahim Ethem Çövüt. Prevalence and Risk Factors of Anemia among Adolescents in Denizli, Turkey. Iran J Pediatr Mar 2012; Vol 22 (No 1), Pp: 77-81

[24] Katai E, Kaplan B, Raick Y, Cohen Y, Neri A, Friedman J. Community screening to reveal iron deficiency in healthy menstruating women in Israel suburbs. European J. Obstetric Gynecology Reprod Biol 1996; 67:21-5.

[25] Mikki N, Abdul-Rahim H.F, Stigum H and G. HolmboeOttesen. Anaemia prevalence and associated sociodemographic and dietary factors among Palestinian adolescents in the West Bank.Eastern MediterraneanHealth Journal 2011;17(3):208-215.

[26] Yearul Kabir, Hussain Mohammad Shahjalal, Farzana Saleh, Wahida Obaid. Dietary pattern, nutritional status, anaemia and anaemia-related knowledge in urban adolescent college girls of Bangladesh. J Pak Med Assoc 2010;60(8):633-8.
[27] Karine Tolentino, Jennifer F. Friedman. An Update on Anemia in Less Developed Countries. Am $J$ Trop Med Hyg. 2007;77(1):44-51.

[28] Sommer A, West KP. Vitamin A Deficiency: Health, Survival and Vision. New York: Oxford University Press; 1996.

[29] Fishman SM, Christian P, West KP. The role of vitamins in the prevention and control of anaemia. Public Health Nutrition $2000 ; 3(2): 125-50$.

[30] Khitam M, Dani C. Helicobacter pylori infection and iron stores: a systematic review and meta-analysis. Helicobacter 2008; 13: 323-40. 